\title{
Physiological Effects of $\gamma$-Aminobutyric Acid Application on Improving Heat and Drought Tolerance in Creeping Bentgrass
}

\author{
Zhou Li \\ Department of Grassland Science, College of Animal Science and Technology, Sichuan \\ Agricultural University, Chengdu, Sichuan, China; and Department of Plant Biology, \\ Rutgers University, 59 Dudley Road, New Brunswick, NJ 08901 \\ Yan Peng ${ }^{1}$ \\ Department of Grassland Science, College of Animal Science and Technology, Sichuan \\ Agricultural University, Chengdu, Sichuan, China \\ Bingru Huang ${ }^{1}$ \\ Department of Plant Biology, Rutgers University, 59 Dudley Road, New Brunswick, NJ 08901 \\ AdDitional INDEX words. chlorophyll, electrolyte leakage, leaf senescence, osmotic adjustment, turf quality
}

\begin{abstract}
Gama-aminobutyric acid (GABA) is a nonprotein amino acid in plant cells, which responds to changes in environmental factors. The objectives of this study were to evaluate the effects of foliar spray of GABA on drought and heat tolerance in creeping bentgrass (Agrostis stolonifera), and to investigate physiological factors altered by GABA application that contribute to improved drought tolerance and heat tolerance. GABA-treated plants (cv. Penncross) or non-GABA-treated control plants were then subjected to the following three treatments in growth chambers: 1) nonstress control [plants irrigated every 2 days to maintain soil water content at the pot capacity and maintained at $21 / 19{ }^{\circ} \mathrm{C}$ (day/night) for 35 days], 2) heat stress [plants exposed to $35 / 30{ }^{\circ} \mathrm{C}$ (day/night) and well-watered conditions for 35 days], and 3) drought stress [plants unirrigated for 9 days and maintained at $21 / 19{ }^{\circ} \mathrm{C}$ (day/night), and then rewatered for 2 days]. As compared with untreated plants, GABA-treated plants showed $22 \%$ to $39 \%$ and $8 \%$ to $21 \%$ significantly lower leaf electrolyte leakage (EL) and $35 \%$ to $143 \%$ and $21 \%$ to $24 \%$ significantly higher turf quality (TQ), $8 \%$ to $17 \%$ and $17 \%$ to $24 \%$ relative water content (RWC), $22 \%$ to $39 \%$ and $25 \%$ to $27 \%$ chlorophyll content, $7 \%$ to $11 \%$ and $6 \%$ to $17 \%$ photochemical efficiency, and an $84 \%$ to $683 \%$ and $57 \%$ to $76 \%$ osmotic adjustment (OA) exposed to heat or drought stress across days of treatment, respectively. GABA-treated plants accumulated $7 \%$ to $10 \%$ more water-soluble carbohydrates (WSC) and $11 \%$ to $43 \%$ more free proline than nontreated plants under heat stress, and $12 \%$ to $30 \%$ higher accumulation of WSC under drought stress. After 2 days of rewatering, a significantly better recovery also was observed in GABA-treated plants than that in nontreated plants previously exposed to drought stress. The results suggest that foliar application of GABA significantly improved heat and drought tolerance of creeping bentgrass, which was associated with maintenance of cell membrane stability, delaying in leaf senescence, and enhancing $O A$. The effectiveness of exogenous GABA application was more pronounced under heat stress than under drought stress.
\end{abstract}

Drought and high temperature are the most common and detrimental abiotic stresses for growth of cool-season plant species in the summer, including heat- and drought-sensitive cool-season turfgrass species, such as creeping bentgrass (Fry and Huang, 2004; Pessarakli, 2007). Drought and heat stress injury are typically characterized by leaf dehydration, reflected as a decline in leaf water content or accelerated leaf senescence due to loss of chlorophyll and photosynthetic activities, as well as decline in membrane stability (Pessarakli, 2007; Rivero et al., 2007; Veerasamy et al., 2007). Leaf wilting and senescence contributes to TQ decline, which negatively affects the playability and functionality of turfgrasses. Therefore, it is important to develop effective strategies to alleviate those

Received for publication 20 Oct. 2015. Accepted for publication 23 Nov. 2015. We thank Jillian Keuogh and Patrick Burgess for critical review of the manuscript and technical assistance in conducting the experiments. We also thank the Chinese Scholarship Council for stipend support to Zhou Li and Rutgers Center for Turfgrass Science for research funding support.

${ }^{1}$ Corresponding author. E-mail: huang@aesop.rutgers.edu; pengyanlee@163. com. physiological damages from drought or heat stress to maintain turfgrass quality in environmental conditions with elevated temperature and limited water resource for irrigation.

Plant growth regulators (PGR) or biostimulants have been used to improve turfgrass tolerance to drought or heat stress, such as trinexapac-ethyl [TE (Bian et al., 2009; Etemadi et al., 2015; Krishnan and Merewitz, 2015)], abscisic acid [ABA (Lu et al., 2009)], cytokinins [CK (Wang et al., 2012; Xu and Huang, 2009; Zhang et al., 2010)], and CK-containing biostimulants (Zhang and Ervin, 2004). Effectiveness and mode of actions of different PGR or biostimulants vary in different turfgrass species and stresses, with TE mainly affecting shoot growth rate and water demand (McCann and Huang, 2008), ABA regulating stomatal closure during drought stress (Kholova et al., 2010), and CK mediating leaf senescence under heat stress (Veerasamy et al., 2007). In recent years, a nonprotein amino acid, GABA, has been found to exhibit PGR effects due to its central roles in maintaining carbon and nitrogen balance and its involvement in carbohydrate and amino acid metabolism (Barbosa et al., 2010; Bouché and Fromm, 2004). In general, GABA is typically produced at a low level under 
favorable environmental conditions, but increases in response to abiotic stresses such as salinity, cold, and drought stress (Kinnersley and Turano, 2000; Serraj et al., 1998; Shi et al., 2010). There is some evidence indicating that GABA is involved in regulation of cytosolic pH (Bouché and Fromm, 2004), protection against oxidative stress (Bouché et al., 2003), and plant defense against insects (McLean et al., 2003). A recent study on functional genomics and metabolomics in Arabidopsis thaliana suggested that GABA may act as a signaling molecule interacting with phytohormones and other metabolites (Batushansky et al., 2014; Renault et al., 2011). Exogenous application of GABA has been found to enhance plant tolerance to abiotic stresses, such as chilling tolerance in peach fruit [Amygdalus persica (Shang et al., 2011)], heat tolerance in rice seedlings [Oryza sativa (Nayyar et al., 2014)], and drought tolerance in black pepper [Piper nigrum (Vijayakumari and Puthur, 2015)]. Krishnan et al. (2013) reported that spraying with GABA improved membrane stability through upregulated peroxidase activity in leaves of perennial ryegrass (Lolium perenne) under drought stress, but no further data supported whether GABA was involved in the regulation of osmolytes or OA since leaf RWC was significantly increased in GABA-treated plants. Hence, limited information is available on the effectiveness of GABA on improving plant tolerance to drought and heat stress in turfgrass. Furthermore, physiological effects of GABA in regulating plant responses to drought or heat stress are not well understood in turfgrass species and other plant species.

Based on the potential biological functions of GABA (Barbosa et al., 2010; Bouché and Fromm, 2004; Bouché et al., 2003; Kinnersley and Turano, 2000; Serraj et al., 1998; Shi et al., 2010), we hypothesize that GABA may regulate drought or heat tolerance in creeping bentgrass through alteration in OA for water retention and suppressing stressaccelerated leaf senescence. The objectives of this study were to evaluate the effectiveness of foliar spray of GABA on drought and heat tolerance in creeping bentgrass, and to investigate physiological factors altered by GABA application for improving drought or heat tolerance.

\section{Materials and Methods}

Plant material and treatment. Creeping bentgrass (cv. Penncross) sod was collected from Horticultural Farm II at Rutgers University, North Brunswick, NJ. The sod pieces were planted in 24 polyvinyl chloride tubes $(30 \mathrm{~cm}$ length and $10 \mathrm{~cm}$ diameter) filled with fritted clay in a greenhouse for 2 months (Sept.-Oct. 2014). The greenhouse had average temperatures of $23 / 16{ }^{\circ} \mathrm{C}$ (day/night) and $790 \mu \mathrm{mol} \cdot \mathrm{m}^{-2} \cdot \mathrm{s}^{-1}$ photosynthetically active radiation $(P A R)$ with natural sunlight and supplemental sodium lights when lack of natural sunlight. Plants were fertilized weekly with half-strength Hoagland's nutrient solution (Hoagland and Arnon, 1950) and trimmed twice per week to maintain a canopy height of $\approx 4 \mathrm{~cm}$. Plants were transferred to controlled growth chambers after 2-month establishment in the greenhouse. The environmental conditions of growth chambers were maintained at day/night temperatures of $21 / 19{ }^{\circ} \mathrm{C}$, $70 \%$ relative humidity, and $12-\mathrm{h}$ photoperiod at $P A R$ of $660 \mathrm{mmol} \cdot \mathrm{m}^{-2} \cdot \mathrm{s}^{-1}$ at the canopy level. Plants were maintained in those conditions for $7 \mathrm{~d}$ to allow plant acclimation to the growth chamber conditions before the imposition of heat and drought treatment.
For the GABA treatment, all plants were sprayed twice at 2-d intervals before exposed to heat or drought stress with 5-10 mL of $0.5 \mathrm{~mm}$ GABA solution or water (non-GABA-treated control) until dripping. The concentration of GABA was chosen based on a preliminary test with a range of concentrations $(0.5$, $1,2,4 \mathrm{~mm})$ for the most effective concentration on phenotypic changes based on TQ and growth. GABA-treated plants or nonGABA-treated control plants were then subjected to the following three treatments in growth chambers: 1) nonstress control (20 May, 27 May, and 3 June 2015)—plants were irrigated every $2 \mathrm{~d}$ to maintain soil water content at pot capacity and maintained at $21 / 19^{\circ} \mathrm{C}$ (day/night) for $35 \mathrm{~d}$; 2) heat stress (21 May, 28 May, and 4 June 2015)—plants were exposed to $35 / 30{ }^{\circ} \mathrm{C}$ (day/night) and well-watered conditions for $35 \mathrm{~d}$; and 3) drought stress (5 May, 9 May, and 12 May 2015)—plants were unirrigated for $9 \mathrm{~d}$ and maintained at $21 / 19^{\circ} \mathrm{C}$ (day/night), and then rewatered for $2 \mathrm{~d}$. The duration of heat and drought stress was determined based on when stress symptoms were observed (mainly based on TQ, the degree of leaf wilt, and the inhibition of growth under stresses).

The experimental design was completely randomized block design with three stress treatments and GABA application under each stress treatment. Each temperature treatment $\left(21 / 19^{\circ} \mathrm{C}\right.$ or $35 / 30{ }^{\circ} \mathrm{C}$ day/night) was replicated in four growth chambers, which served as experimental systems or units. Four pots or replicates of drought-stressed or nonstressed plants were placed in four growth chambers set at $21 / 19{ }^{\circ} \mathrm{C}$ (day/night). GABA treatment was replicated in four pots for each stress treatment (nonstress control, drought, or heat) that were replicated in four growth chambers.

Physiological analysis. Turf quality was evaluated based on color, density, and uniformity of the grass using a scale of 1 to $9[9=$ fully turgid, dense green canopy; $6=$ minimal acceptable level; 1 = completely desiccated and brown plants (Beard, 2001)]. For leaf RWC measurement, leaves were detached from the plant and immediately weighed for fresh weight $(\mathrm{FW})$ and then immersed in deionized water for $12 \mathrm{~h}$ at $4{ }^{\circ} \mathrm{C}$. Turgid leaves were blotted dry and weighed for turgid weight (TW), then leaf tissues were dried in an oven at $80^{\circ} \mathrm{C}$ for at least $72 \mathrm{~h}$ to get a dry weight (DW). Leaf RWC was calculated using the formula RWC $(\%)=[(\mathrm{FW}-\mathrm{DW}) /$ $(\mathrm{TW}-\mathrm{DW})] \times 100$ (Barrs and Weatherley, 1962).

EL was used for estimating cell membrane stability of leaves. Fresh leaves $(0.1 \mathrm{~g})$ were washed three times with deionized water and immersed in $35 \mathrm{~mL}$ of deionized water and shaken for $24 \mathrm{~h}$. The conductance of the solution was measured as initial conductivity $\left(\mathrm{C}_{\text {initial }}\right)$ using a conductivity meter (model 32; Yellow Springs Instrument Co., Yellow Spring, $\mathrm{OH})$. Leaves then were autoclaved at $120^{\circ} \mathrm{C}$ for $20 \mathrm{~min}$. Once at room temperature, the conductivity of tissues was measured as maximum conductance $\left(\mathrm{C}_{\max }\right)$. EL was calculated as the percentage of $\mathrm{C}_{\text {initial }} / \mathrm{C}_{\max }$ (Blum and Ebercon, 1981).

Chlorophyll was immerged in $10 \mathrm{~mL}$ of dimethyl sulfoxide and left in the dark for $48 \mathrm{~h}$, and then the leaf extract was measured at 663 and $645 \mathrm{~nm}$ with a spectrophotometer (Spectronic Instruments, Rochester, NY). Chlorophyll content was calculated using the formula described by Arnon (1949). A chlorophyll fluorescence meter (Fim 1500; Dynamax, Houston, TX) was used for measuring photochemical efficiency $\left(\mathrm{F}_{\mathrm{v}} / \mathrm{F}_{\mathrm{m}}\right)$. Individual leaves were adapted to darkness for 30 min using leaf clips and the $F_{v} / F_{m}$ ratio was recorded with the fluorescence meter. Three measurements of $\mathrm{F}_{\mathrm{v}} / \mathrm{F}_{\mathrm{m}}$ ratio were taken per replicate at each sampling day. 
The content of WSC was determined according to the method of Buysse and Merckx (1993) with some modification. Leaves (20 mg DW) were added into $10 \mathrm{~mL} 80 \%$ ethanol and then extracted in boiled water $\left(100{ }^{\circ} \mathrm{C}\right)$ for $15 \mathrm{~min}$. After centrifugation at $3600 \mathrm{~g}_{\mathrm{n}}$ for $10 \mathrm{~min}$, supernatants were collected for further analysis. The reaction mixture contained $1 \mathrm{~mL}$ of supernatant, $1 \mathrm{~mL}$ of $18 \%$ phenol solution, and $5 \mathrm{~mL}$ concentrated sulfuric acid. The mixture was shaken, and absorbance was read at $490 \mathrm{~nm}$ using a spectrophotometer (Spectronic Instruments).

Free proline content was quantified spectrophotometrically using the ninhydrin method according to Bates et al. (1973). Fresh leaves $(0.1 \mathrm{~g})$ were immerged in $5 \mathrm{~mL} 3 \%$ aqueous sulfosalicylic acid and then heated in a water bath $\left(100{ }^{\circ} \mathrm{C}\right)$ for $20 \mathrm{~min}$. After centrifugation at $12,000 \mathrm{~g}_{\mathrm{n}}$, the supernatant was used for the estimation of the proline concentration. The reaction mixture consisted of $1 \mathrm{~mL}$ of supernatant, $1.5 \mathrm{~mL}$ of $2.5 \%$ acid ninhydrin, and $1 \mathrm{~mL}$ of glacial acetic acid, which was heated at $100{ }^{\circ} \mathrm{C}$ for $40 \mathrm{~min}$. The reaction mixture was immediately cooled down in an ice bath, and extracted with $2.5 \mathrm{~mL}$ of toluene then absorbance was read at $520 \mathrm{~nm}$.

For determination of OA, fresh leaf tissues were submerged in deionized water for $8 \mathrm{~h}$ at $4{ }^{\circ} \mathrm{C}$ to fully hydrate leaves. Tissues were blotted dry and frozen in liquid nitrogen for further analysis. Following thawing in ice bath, leaves were ground with a micropestle to extract leaf sap and $10 \mathrm{~mL}$ sap from a $1.5-\mathrm{mL}$ tube was inserted into an osmometer (Wescor, Logan, UT) to determine osmolality (millimoles per kilogram). According to the formula $\psi_{\mathrm{S}}$ (megapascals) $=[$ (osmolality) (0.001) (2.58)], osmolality was converted to $\psi_{\mathrm{S}}$. OA was then calculated as the difference in $\psi_{\mathrm{S}}$ at full turgor between stressed leaves and well-watered control leaves (Blum, 1989).

Statistical Analysis. The General Linear Model procedure of SAS (version 9.1; SAS Institute, Cary, NC) was used to determine the significance of main treatment effects and interactions between GABA and heat or drought stress for all measured parameters. The significance of differences between GABA treatments under nonstress control, drought, or heat stress were tested using the least significance test with $P=0.05$ at a given day of stress treatment.

\section{Results}

EFFECTS OF FOLIAR GABA APPLICATION ON TURF GROWTH AND PHYSIOLOGICAL FACTORS UNDER NONSTRESS CONDITION. All parameters evaluated in this study, including TQ (Fig. 1A), RWC (Fig. 2A), EL (Fig. 3A), chlorophyll content (Fig. 4A), $\mathrm{F}_{\mathrm{v}} / \mathrm{F}_{\mathrm{m}}$ (Fig. 5A), WSC content (Fig. 6A), and free proline content (Fig. 7A), remained relative constant during the course (35 d) of nonstress treatment. Foliar application of GABA had no significant effects on those parameters under nonstress conditions.

EFFECTS OF GABA ON TQ AND EL UNDER DROUGHT OR HEAT STRESS. TQ decreased gradually with prolonged heat stress duration for GABA-treated or nontreated plants, but GABAtreated plants maintained a significantly higher TQ than nontreated plants during $35 \mathrm{~d}$ of heat stress; TQ was $35 \%, 90 \%$, and $143 \%$ higher from 21 to $35 \mathrm{~d}$ of heat stress, respectively (Fig. 1B). TQ declined with drought duration, but GABA-treated plants showed a $21 \%$ higher TQ at $5 \mathrm{~d}$ of drought and $124 \%$ higher at $9 \mathrm{~d}$ of drought when compared with nontreated plants (Fig. 1C). GABA-treated plants previously exposed to drought stress
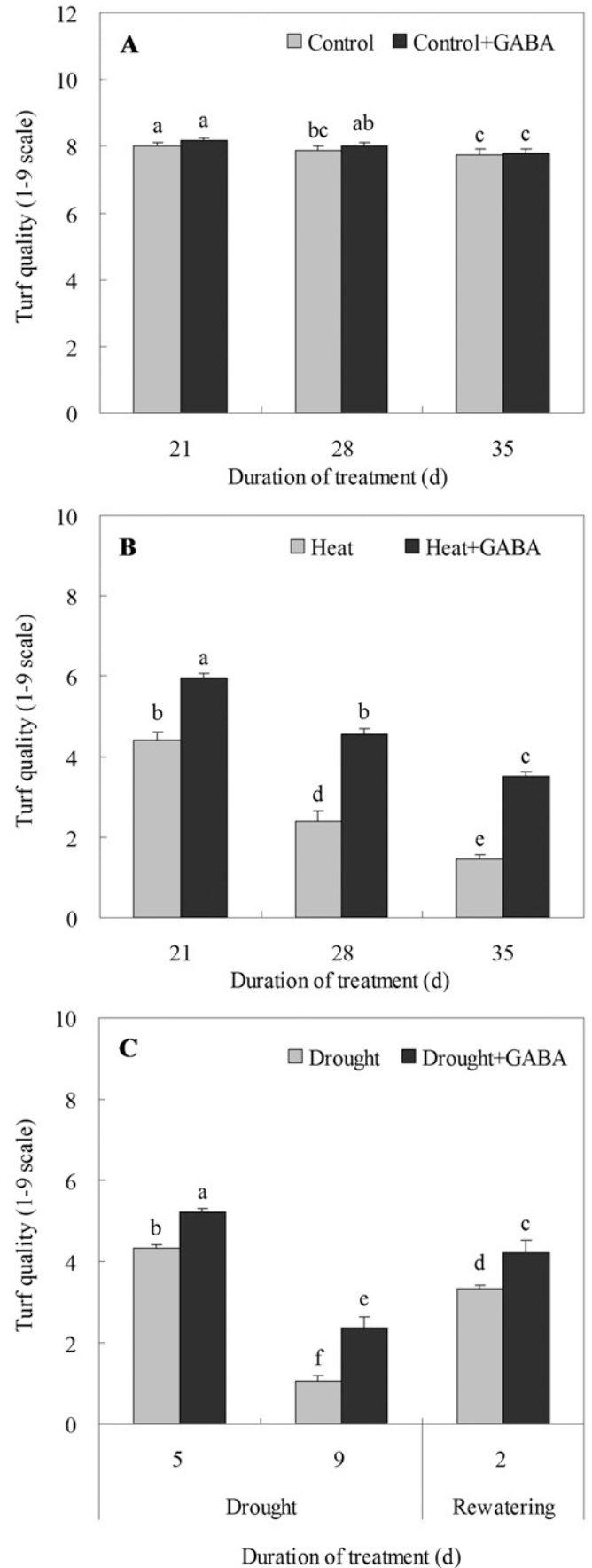

Fig. 1. The effects of $\gamma$-aminobutyric acid (GABA) on turf quality (TQ) (A) under well-watered condition, (B) under heat stress, and $(\mathbf{C})$ under drought stress in creeping bentgrass under normal water condition, heat stress, and drought stress. TQ was evaluated based on color, density, and uniformity of the grass using a scale of 1 to 9 ; 9 being fully turgid, dense green canopy, 6 being minimal acceptable level, and 1 being completely desiccated and brown plants. Means of four independent samples are presented. Bars represent standard errors. The same letters above columns indicate no significant difference at $P=0.05$ based on least significant difference. Control, plants were maintained at $21 / 19{ }^{\circ} \mathrm{C}$ (day/night) for $35 \mathrm{~d}$ under well-watered conditions; heat, plants were exposed to $35 / 30^{\circ} \mathrm{C}$ (day/night) under well-watered conditions for $35 \mathrm{~d}$; drought, plants were unirrigated for $9 \mathrm{~d}$ and maintained at $21 / 19^{\circ} \mathrm{C}$ (day/night) and then rewatered for $2 \mathrm{~d}$; Control + GABA, GABA-treated plants maintained at $21 / 19{ }^{\circ} \mathrm{C}$ (day/night) for $35 \mathrm{~d}$ under well-watered conditions; heat + GABA, GABAtreated plants were exposed to $35 / 30{ }^{\circ} \mathrm{C}$ (day/night) under well-watered conditions for $35 \mathrm{~d}$; drought + GABA, GABA-treated plants unirrigated for $9 \mathrm{~d}$ and maintained at $21 / 19^{\circ} \mathrm{C}$ (day/night) and then rewatered for $2 \mathrm{~d}$. 

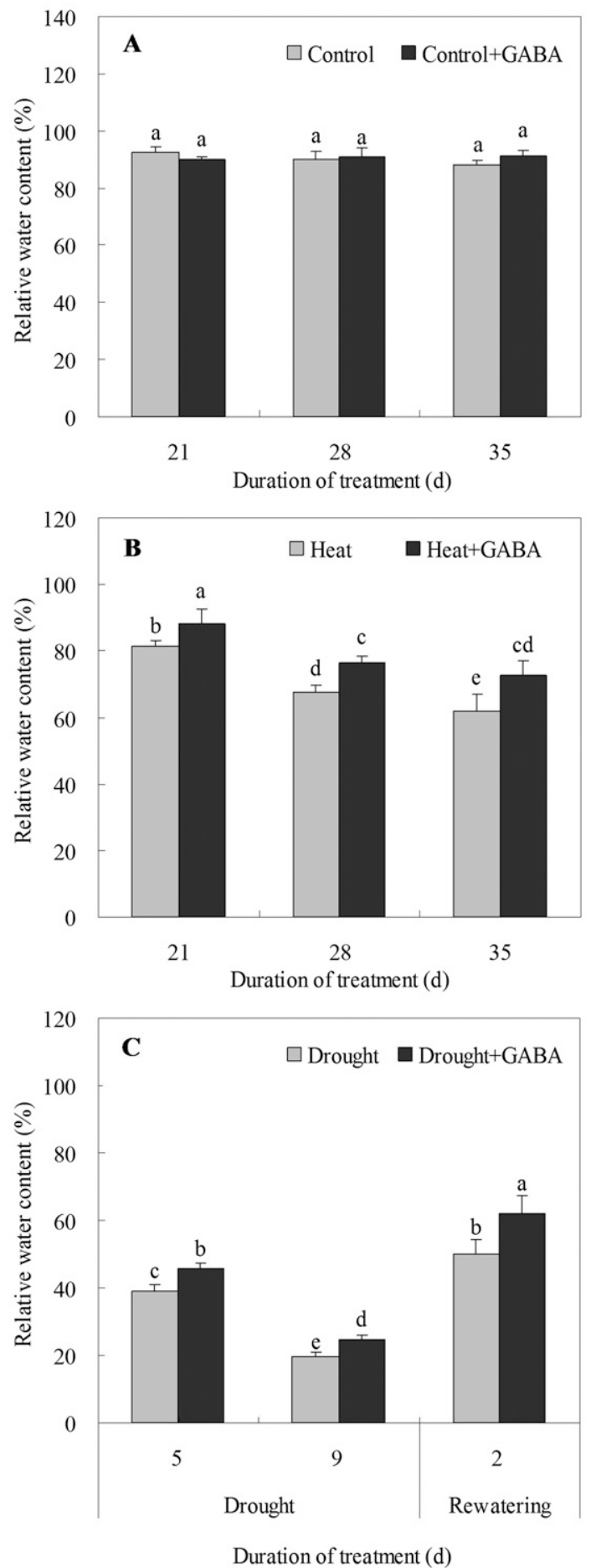

Fig. 2. The effects of $\gamma$-aminobutyric acid (GABA) on relative water content (A) under well-watered condition, (B) under heat stress, and $(\mathbf{C})$ under drought stress in creeping bentgrass under normal water condition, heat stress, and drought stress. Means of four independent samples are presented. Bars represent standard errors. The same letters above columns indicate no significant difference at $P=$ 0.05 based on least significant difference. Control, plants were maintained at 21/ $19{ }^{\circ} \mathrm{C}$ (day/night) for $35 \mathrm{~d}$ under well-watered conditions; heat, plants were exposed to $35 / 30^{\circ} \mathrm{C}$ (day/night) under well-watered conditions for $35 \mathrm{~d}$; drought, plants were unirrigated for $9 \mathrm{~d}$ and maintained at $21 / 19^{\circ} \mathrm{C}$ (day/night) and then rewatered for $2 \mathrm{~d}$; control $+\mathrm{GABA}$, GABA-treated plants maintained at $21 / 19^{\circ} \mathrm{C}$ (day/night) for $35 \mathrm{~d}$ under well-watered conditions; heat + GABA, GABA-treated plants were exposed to $35 / 30{ }^{\circ} \mathrm{C}$ (day/night) under well-watered conditions for $35 \mathrm{~d}$; drought + GABA, GABA-treated plants unirrigated for $9 \mathrm{~d}$ and maintained at $21 / 19{ }^{\circ} \mathrm{C}$ (day/night) and then rewatered for $2 \mathrm{~d}$.
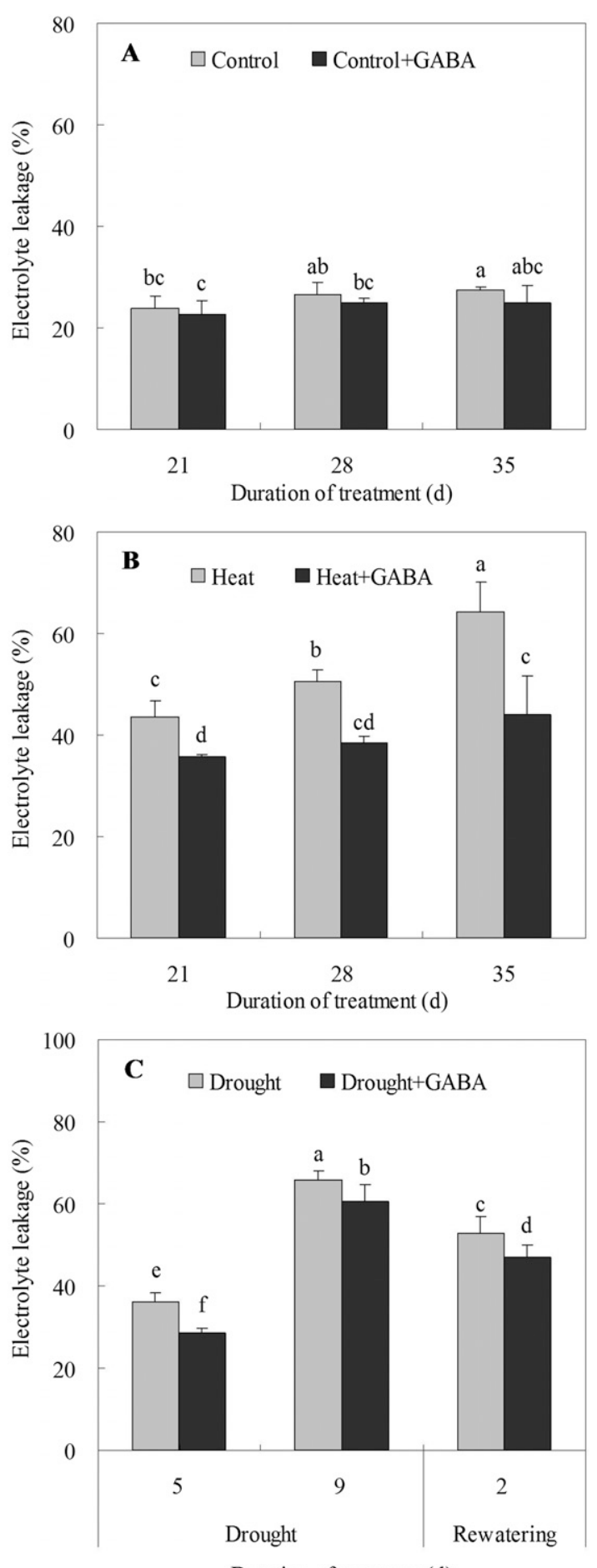

Duration of treatment (d)

Fig. 3. The effects of $\gamma$-aminobutyric acid (GABA) on electrolyte leakage (A) under well-watered condition, (B) under heat stress, and (C) under drought stress in creeping bentgrass under normal water condition, heat stress, and drought stress. Means of four independent samples are presented. Bars represent standard errors. The same letters above columns indicate no significant difference at $P=$ 0.05 based on least significant difference. Control, plants were maintained at 21/ $19{ }^{\circ} \mathrm{C}$ (day/night) for $35 \mathrm{~d}$ under well-watered conditions; heat, plants were exposed to $35 / 30{ }^{\circ} \mathrm{C}$ (day/night) under well-watered conditions for $35 \mathrm{~d}$; drought, plants were unirrigated for $9 \mathrm{~d}$ and maintained at $21 / 19^{\circ} \mathrm{C}$ (day/night) and then rewatered for $2 \mathrm{~d}$; control $+\mathrm{GABA}, \mathrm{GABA}$-treated plants maintained at $21 / 19^{\circ} \mathrm{C}$ (day/night) for $35 \mathrm{~d}$ under well-watered conditions; heat + GABA, GABA-treated plants were exposed to $35 / 30{ }^{\circ} \mathrm{C}$ (day/night) under well-watered conditions for $35 \mathrm{~d}$; drought + GABA, GABA-treated plants unirrigated for $9 \mathrm{~d}$ and maintained at $21 / 19^{\circ} \mathrm{C}$ (day/night) and then rewatered for $2 \mathrm{~d}$. 

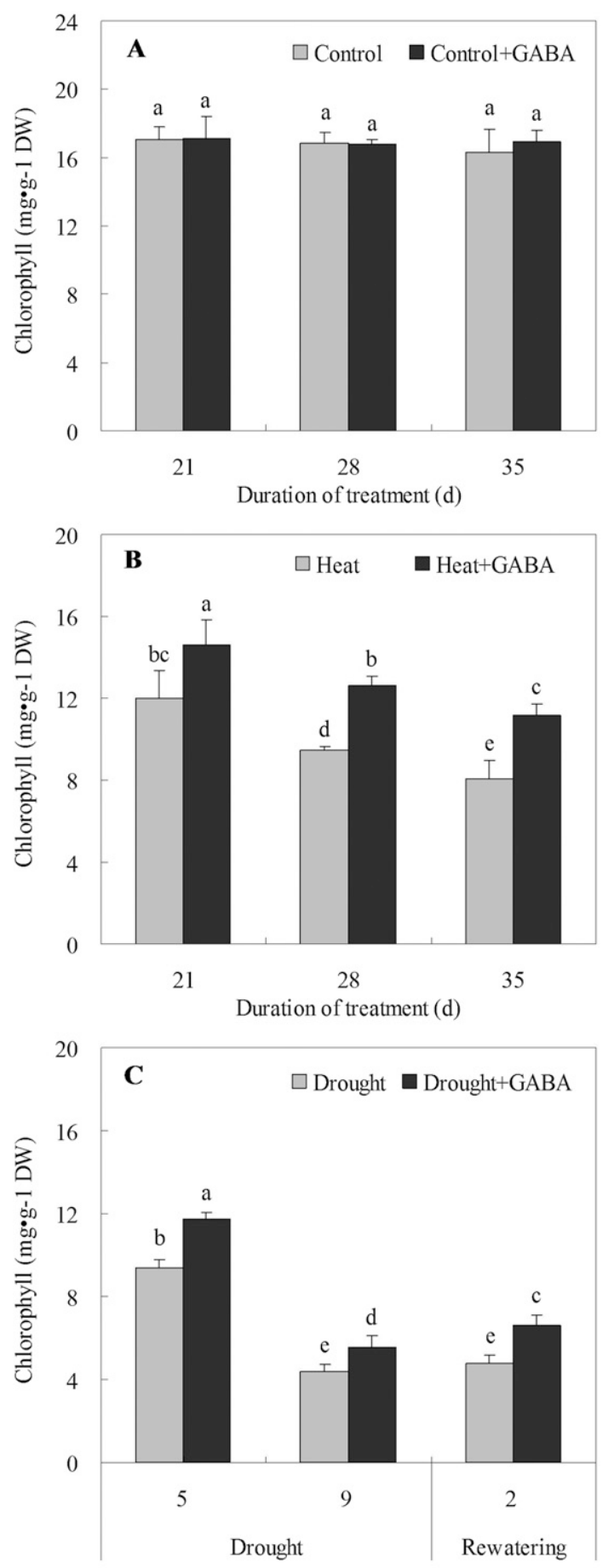

Duration of treatment (d)

Fig. 4. The effects of $\gamma$-aminobutyric acid (GABA) on chlorophyll content (A) under well-watered condition, $(\mathbf{B})$ under heat stress, and $(\mathbf{C})$ under drought stress in creeping bentgrass under normal water condition, heat stress, and drought stress. Means of four independent samples are presented. Bars represent standard errors. The same letters above columns indicate no significant difference at $P=$ 0.05 based on least significant difference. Control, plants were maintained at 21/ $19{ }^{\circ} \mathrm{C}$ (day/night) for $35 \mathrm{~d}$ under well-watered conditions; heat, plants were exposed to $35 / 30^{\circ} \mathrm{C}$ (day/night) under well-watered conditions for $35 \mathrm{~d}$; drought, plants were unirrigated for $9 \mathrm{~d}$ and maintained at $21 / 19^{\circ} \mathrm{C}$ (day/night) and then rewatered for $2 \mathrm{~d}$; control $+\mathrm{GABA}, \mathrm{GABA}$-treated plants maintained at $21 / 19^{\circ} \mathrm{C}$ (day/night) for $35 \mathrm{~d}$ under well-watered conditions; heat + GABA, GABA-treated plants were exposed to $35 / 30{ }^{\circ} \mathrm{C}$ (day/night) under well-watered conditions for $35 \mathrm{~d}$; drought + GABA, GABA-treated plants unirrigated for $9 \mathrm{~d}$ and maintained at $21 / 19^{\circ} \mathrm{C}$ (day/night) and then rewatered for $2 \mathrm{~d}$.
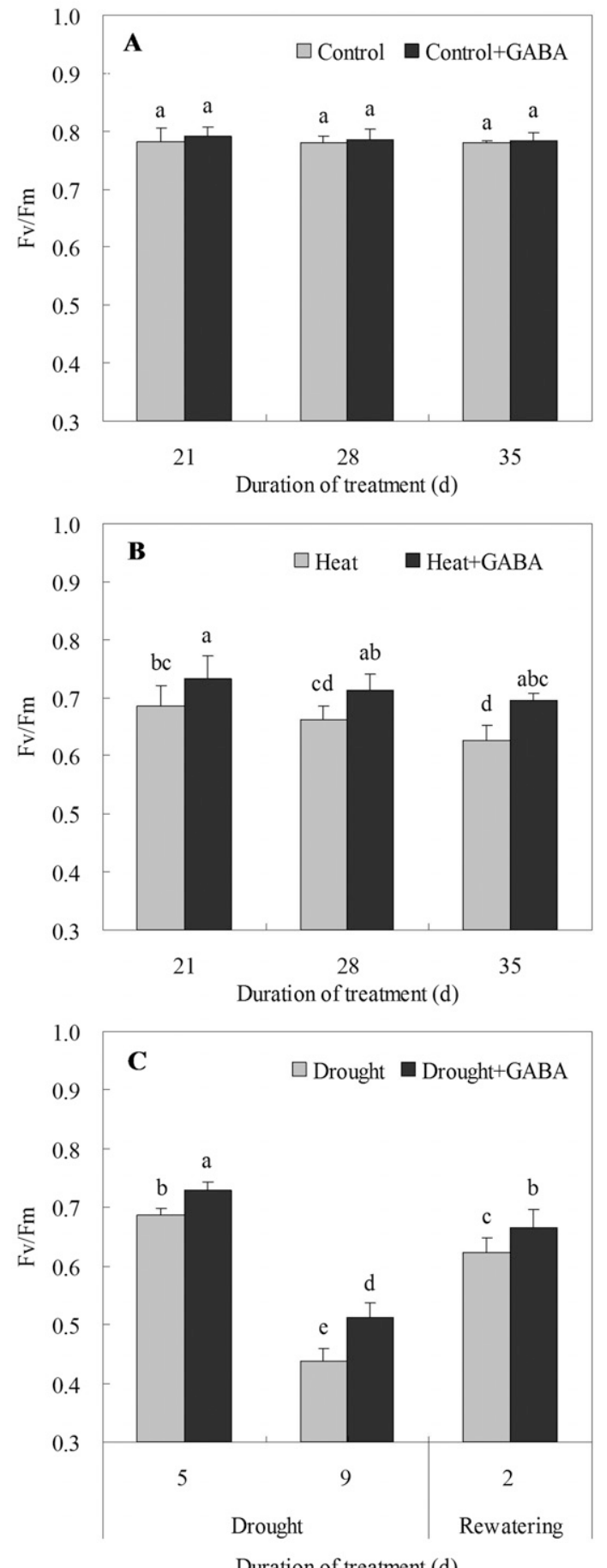

Fig. 5. The effects of $\gamma$-aminobutyric acid (GABA) on photochemical efficiency $\left(\mathrm{F}_{\mathrm{v}} / \mathrm{F}_{\mathrm{m}}\right)(\mathbf{A})$ under well-watered condition, $(\mathbf{B})$ under heat stress, and $(\mathbf{C})$ under drought stress in creeping bentgrass under normal water condition, heat stress, and drought stress. Means of four independent samples are presented. Bars represent standard errors. The same letters above columns indicate no significant difference at $P=0.05$ based on least significant difference. Control, plants were maintained at $21 / 19{ }^{\circ} \mathrm{C}$ (day/night) for $35 \mathrm{~d}$ under well-watered conditions; heat, plants were exposed to $35 / 30{ }^{\circ} \mathrm{C}$ (day/night) under well-watered conditions for $35 \mathrm{~d}$; drought, plants were unirrigated for $9 \mathrm{~d}$ and maintained at $21 / 19{ }^{\circ} \mathrm{C}$ (day/night) and then rewatered for $2 \mathrm{~d}$; control $+\mathrm{GABA}$, GABA-treated plants maintained at $21 / 19^{\circ} \mathrm{C}$ (day/night) for $35 \mathrm{~d}$ under well-watered conditions; heat + GABA, GABA-treated plants were exposed to $35 / 30{ }^{\circ} \mathrm{C}$ (day/night) under well-watered conditions for $35 \mathrm{~d}$; drought + GABA, GABA-treated plants unirrigated for $9 \mathrm{~d}$ and maintained at $21 / 19^{\circ} \mathrm{C}$ (day/night) and then rewatered for $2 \mathrm{~d}$. 

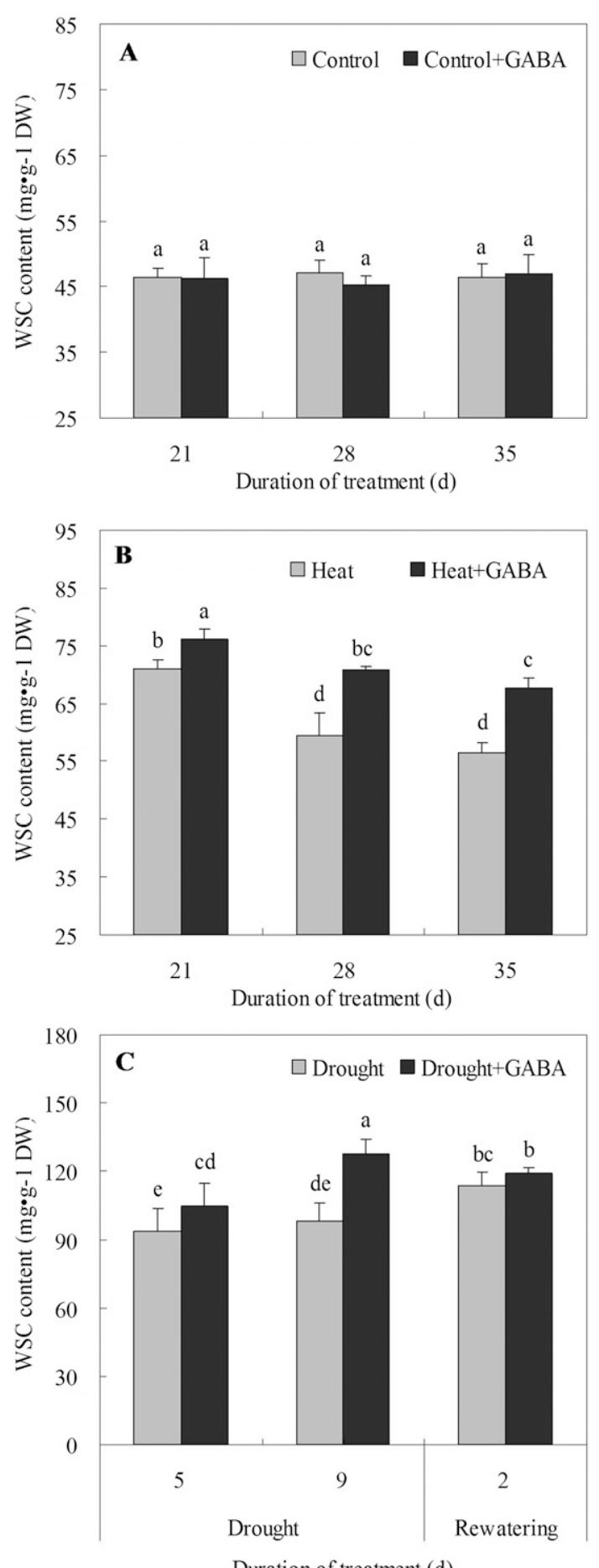

Duration of treatment (d)

Fig. 6. The effects of $\gamma$-aminobutyric acid (GABA) on water-soluble carbohydrate (WSC) (A) under well-watered condition, (B) under heat stress, and (C) under drought stress in creeping bentgrass under normal water condition, heat stress, and drought stress. Means of four independent samples are presented. Bars represent standard errors. The same letters above columns indicate no significant difference at $P=0.05$ based on least significant difference. Control, plants were maintained at $21 / 19^{\circ} \mathrm{C}$ (day/night) for $35 \mathrm{~d}$ under well-watered conditions; heat, plants were exposed to $35 / 30{ }^{\circ} \mathrm{C}$ (day/night) under wellwatered conditions for $35 \mathrm{~d}$; drought, plants were unirrigated for $9 \mathrm{~d}$ and maintained at $21 / 19{ }^{\circ} \mathrm{C}$ (day/night) and then rewatered for $2 \mathrm{~d}$; control + GABA, GABA-treated plants maintained at $21 / 19{ }^{\circ} \mathrm{C}$ (day/night) for $35 \mathrm{~d}$ under well-watered conditions; heat + GABA, GABA-treated plants were exposed to $35 / 30{ }^{\circ} \mathrm{C}$ (day/night) under well-watered conditions for $35 \mathrm{~d}$; drought + GABA, GABA-treated plants unirrigated for $9 \mathrm{~d}$ and maintained at $21 / 19^{\circ} \mathrm{C}$ (day/night) and then rewatered for $2 \mathrm{~d}$.
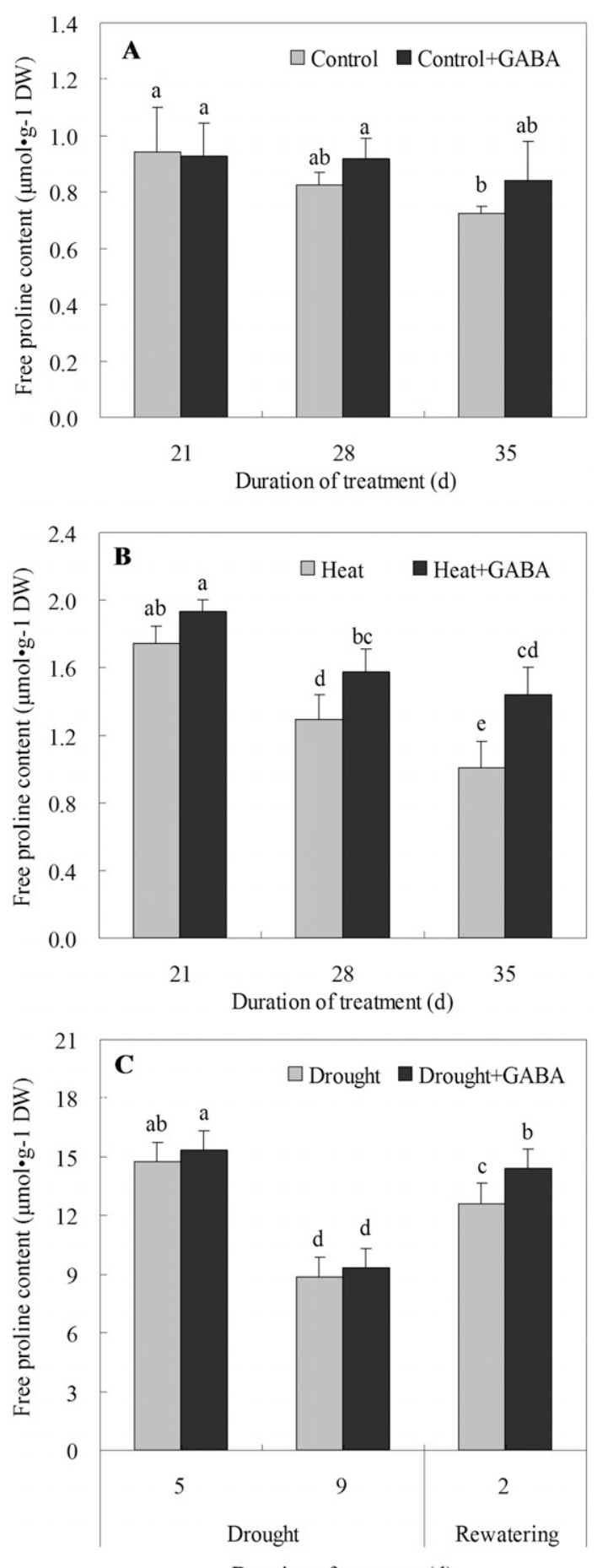

Fig. 7. The effects of $\gamma$-aminobutyric acid (GABA) on free proline (A) under well-watered condition, (B) under heat stress, and (C) under drought stress in creeping bentgrass under normal water condition, heat stress, and drought stress. Means of four independent samples are presented. Bars represent standard errors. The same letters above columns indicate no significant difference at $P=0.05$ based on least significant difference. Control, plants were maintained at $21 / 19{ }^{\circ} \mathrm{C}$ (day/night) for $35 \mathrm{~d}$ under well-watered conditions; heat, plants were exposed to $35 / 30{ }^{\circ} \mathrm{C}$ (day/night) under wellwatered conditions for $35 \mathrm{~d}$; drought, plants were unirrigated for $9 \mathrm{~d}$ and maintained at $21 / 19^{\circ} \mathrm{C}$ (day/night) and then rewatered for $2 \mathrm{~d}$; control + GABA, GABA-treated plants maintained at $21 / 19{ }^{\circ} \mathrm{C}$ (day/night) for $35 \mathrm{~d}$ under well-watered conditions; heat + GABA, GABA-treated plants were exposed to $35 / 30{ }^{\circ} \mathrm{C}$ (day/night) under well-watered conditions for $35 \mathrm{~d}$; drought + GABA, GABA-treated plants unirrigated for $9 \mathrm{~d}$ and maintained at $21 / 19{ }^{\circ} \mathrm{C}$ (day/night) and then rewatered for $2 \mathrm{~d}$. 
also recovered to a higher TQ than nontreated control plants after $2 \mathrm{~d}$ of rewatering. Leaf EL increased during $35 \mathrm{~d}$ of heat stress (Fig. 3B) and $9 \mathrm{~d}$ of drought stress (Fig. 3C) regardless of GABA treatment. GABA application resulted in significant decrease in EL under heat or drought stress, which were 18\%, $24 \%$, and $32 \%$ lower than nontreated plants at 21,28 , and $35 \mathrm{~d}$ of heat stress and $21 \%$ and $8 \%$ lower at 5 and $9 \mathrm{~d}$ of drought stress, respectively (Fig. 3B and C).

EFFECTS OF GABA ON CHLOROPHYLL AND PHOTOCHEMICAL EFFICIENCY UNDER DROUGHT AND HEAT STRESS. Leaf chlorophyll content declined with prolonged duration during heat (Fig. 4B) and drought stress (Fig. 4C) in GABA-treated and nontreated plants. Compared with nontreated plants, GABA-treated plants had $22 \%, 34 \%$, and $39 \%$ higher chlorophyll content at 21,28 , and $35 \mathrm{~d}$ of heat stress, and $25 \%$ and $27 \%$ higher chlorophyll content at 5 and $9 \mathrm{~d}$ of drought stress, respectively (Fig. 4B and C). GABA application also enhanced chlorophyll content at $2 \mathrm{~d}$ of rewatering following $9 \mathrm{~d}$ of drought stress (Fig. 4C). Leaf $\mathrm{F}_{\mathrm{v}} / \mathrm{F}_{\mathrm{m}}$ declined significantly from 21 to $35 \mathrm{~d}$ of heat stress in plants without GABA treatment, whereas $\mathrm{F}_{\mathrm{v}} / \mathrm{F}_{\mathrm{m}}$ did not change in GABA-treated plants during $35 \mathrm{~d}$ of heat stress (Fig. 5B). Under drought stress, $F_{v} / F_{m}$ in both GABA-treated and nontreated plants declined significantly with stress duration from 5 to $9 \mathrm{~d}$; exogenous GABA significantly increased $\mathrm{F}_{\mathrm{v}} / \mathrm{F}_{\mathrm{m}}$, compared with nontreated plants at both 5 and $9 \mathrm{~d}$ of drought. In addition, a significantly higher $\mathrm{F}_{\mathrm{v}} / \mathrm{F}_{\mathrm{m}}$ ratio also was observed in GABA-treated plants than that in nontreated plants after $2 \mathrm{~d}$ of rewatering (Fig. 5C).

EFFECTS OF GABA ON WATER-SOLUBLE CARBOHYDRATE AND FREE PROLINE ACCUMULATION. The content of WSC and proline did not change significantly under nonstress conditions (Figs. 6A and 7A). The content of WSC decreased in leaves of creeping bentgrass during 21 to $35 \mathrm{~d}$ of heat stress, whereas it was unchanged during 5 to $9 \mathrm{~d}$ of drought stress (Fig. 6). WSC content was $7 \%, 19 \%$, and $10 \%$ significantly higher in plants treated with GABA compared with nontreated ones at 21, 28, and $35 \mathrm{~d}$ of heat stress (Fig. 6B). The application of GABA also resulted in $12 \%$ and $30 \%$ higher WSC content in GABA-treated plants than nontreated plants at 5 and $9 \mathrm{~d}$ of drought stress. Significant difference of WSC content between two treatments was not observed after $2 \mathrm{~d}$ of rewatering (Fig. 6C). Proline content decreased significantly from 21 to $35 \mathrm{~d}$ of heat or 5 to $9 \mathrm{~d}$ of drought stress (Fig. 7B and C). Exogenous GABA increased proline accumulation in plants under heat stress, but had no effects on proline accumulation under drought stress, although GABAtreated plants had greater proline content at rewatering (Fig. 7C).

EFFECTS OF FOLIAR GABA APPLICATION ON LEAF RWC AND OA UNDER DROUGHT OR HEAT STRESS. Leaf RWC declined with stress duration for both drought and heat stress in GABA-treated or nontreated plants, but exogenous application of GABA effectively suppressed the decline in RWC (Fig. 2B and C). GABA-treated plants exhibited significantly higher RWC compared with nontreated plants during $35 \mathrm{~d}$ of heat stress and $9 \mathrm{~d}$ of drought stress.

Application of GABA significantly increased OA in leaves under heat or drought stress. The OA of GABA-treated plants increased by 2-, 8-, and 5-fold compared with that of nontreated plants at 21, 28, and $35 \mathrm{~d}$ of heat stress, respectively (Fig. 8A). Under drought stress, there was an increase in OA for the GABA-treated plants, which was two times higher at $5 \mathrm{~d}$. This increase was also found in the treated plants at $9 \mathrm{~d}$ with a 2 -fold increase. GABA application had no effects on OA as plants were rewatered (Fig. 8B).
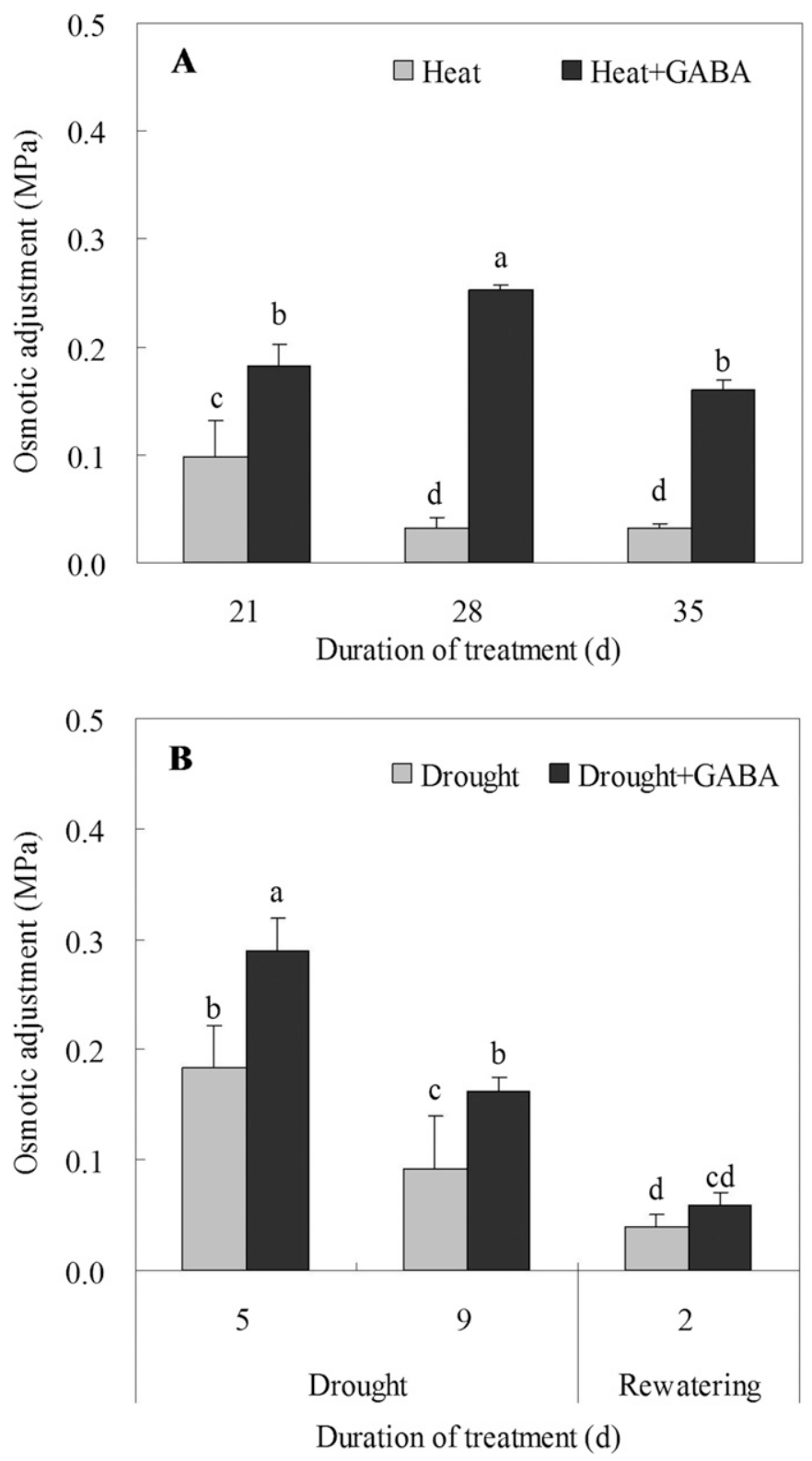

Fig. 8. The effects of $\gamma$-aminobutyric acid (GABA) on osmotic adjustment (OA) (A) under heat stress and (B) under drought stress in creeping bentgrass under normal water condition, heat stress, and drought stress. Means of four independent samples are presented. Bars represent standard errors. The same letters above columns indicate no significant difference at $P=0.05$ based on least significant difference. Control, plants were maintained at $21 / 19{ }^{\circ} \mathrm{C}$ (day/night) for $35 \mathrm{~d}$ under well-watered conditions; heat, plants were exposed to $35 / 30{ }^{\circ} \mathrm{C}$ (day/night) under well-watered conditions for $35 \mathrm{~d}$; drought, plants were unirrigated for $9 \mathrm{~d}$ and maintained at $21 / 19^{\circ} \mathrm{C}$ (day/night) and then rewatered for $2 \mathrm{~d}$; control + GABA, GABAtreated plants maintained at $21 / 19{ }^{\circ} \mathrm{C}$ (day/night) for $35 \mathrm{~d}$ under wellwatered conditions; heat + GABA, GABA-treated plants were exposed to $35 / 30{ }^{\circ} \mathrm{C}$ (day/night) under well-watered conditions for $35 \mathrm{~d}$; drought + GABA, GABA-treated plants unirrigated for $9 \mathrm{~d}$ and maintained at $21 / 19{ }^{\circ} \mathrm{C}$ (day/night) and then rewatered for $2 \mathrm{~d}$.

\section{Discussion}

Enhanced stress tolerance induced by application of GABA has been reported in different species and stress conditions, such as in Caragana intermedia under $\mathrm{NaCl}$ stress (Shi et al., 
2010), in barley seedlings (Hordeum vulgare) under aluminum stress (Song et al., 2010), and in perennial ryegrass under drought stress (Krishnan et al., 2013). In this study, TQ was increased significantly by GABA application under either heat or drought stress, suggesting that GABA was effective in improving creeping bentgrass tolerance to heat or drought stress. However, physiological mechanisms of GABA-regulating drought or heat tolerance, particularly for stress-sensitive perennial grasses are still not well understood. As discussed in the introduction, leaf senescence and dehydration are the typical symptoms of heat and drought stress (Rivero et al., 2007; Veerasamy et al., 2007). Maintaining cell membrane integrity is critically important to maintain leaf hydration for cell turgor maintenance and chloroplast integrity to protect leaves from loss of chlorophyll and photosynthetic activities (Blum and Ebercon, 1981; Rensburg et al., 1993). In this study, exogenous application of GABA was effective in decreasing EL under heat or drought stress, implying that GABA could protect leaf membranes from heat or drought damages, which could be associated with both the maintenance of leaf hydration and mitigation of stress-induced leaf senescence, as discussed below.

Both chlorophyll content and $\mathrm{F}_{\mathrm{v}} / \mathrm{F}_{\mathrm{m}}$ declined with increasing drought or heat duration, indicating that both stresses accelerated leaf senescence in creeping bentgrass. Foliar application of GABA suppressed heat- or drought-induced leaf senescence, as manifested by the higher chlorophyll content and $\mathrm{F}_{\mathrm{v}} / \mathrm{F}_{\mathrm{m}}$ ratio, as well as lower EL in GABA-treated plants compared with nontreated plants. The metabolic mechanisms of how GABA may be involved in protecting leaves from senescence are yet unknown. Bouché et al. (2003) suggested that GABA may play roles in protecting plants against oxidative stress. Whether GABA may activate antioxidant defense mechanisms for heat or drought tolerance in creeping bentgrass deserves further investigation.

Maintenance of favorable water status is also essential for plant tolerance to heat or drought stress, which is not only controlled by cell membrane integrity and also through OA associated with the accumulation of compatible solutes, such as sugars and proline (Nilsen and Orcutt, 1996). In this study, RWC declined with drought stress to $\approx 40 \%$ by $5 \mathrm{~d}$ and $20 \%$ by $9 \mathrm{~d}$ indicating that creeping bentgrass experienced moderate-tosevere water deficit, as reported in Merewitz et al. (2011), which showed RWC of creeping bentgrass mature leaves declined to these levels at water potentials of the growing medium ranging from -1.0 to $-1.6 \mathrm{MPa}$; RWC declined to $60 \%$ to $80 \%$ after $21 \mathrm{~d}$ of heat stress, suggesting heat-stressed plants suffered from mild water deficit. GABA application increased leaf RWC and OA in creeping bentgrass exposed to heat or drought stress, suggesting that enhanced OA could contribute to the maintenance of greater RWC. WSC and proline are well known to be the most important compatible osmolytes relative to OA (Chen and Murata, 2002). Exogenous TE-induced enhancement in drought tolerance and is involved in accumulation of WSC in creeping bentgrass (Bian et al., 2009). Drought-preconditioning-enhanced heat tolerance in kentucky bluegrass, which is related to the maintenance of higher WSC and proline with active OA during heat stress (Jiang and Huang, 2001). Krishnan et al. (2013) reported that mitigation of drought stress damage by exogenous GABA is involved in maintaining cell turgor, but there is no direct explanation for this effect in their study. In the present study, GABA-treated plants exhibited significantly higher WSC and proline under heat stress, suggesting that both WSC and proline could contribute to GABA-induced OA. Nayyar et al. (2014) also found that GABA application raised the endogenous levels of proline under heat stress associated with improved heat tolerance in rice seedlings. However, under drought stress, the increased OA was mainly related to greater WSC content, not proline, in GABA-treated plants.

Overall, foliar application of GABA was effective in improving heat and drought tolerance of creeping bentgrass associated with maintenance of cell membrane stability, suppressing leaf senescence, and enhanced OA associated with the accumulation of WSC or proline. Additional studies are required regarding metabolic and molecular mechanisms of GABA regulation of drought or heat tolerance in cool-season turfgrass and other plant species.

\section{Literature Cited}

Arnon, D.I. 1949. Copper enzymes in isolated chloroplasts. Polyphenoloxidase in Beta vulgaris. Plant Physiol. 24:1-13.

Barbosa, J.M., N.K. Singh, J.H. Cherry, and R.D. Locy. 2010. Nitrate uptake and utilization is modulated by exogenous $\gamma$-aminobutyric acid in Arabidopsis thaliana seedlings. Plant Physiol. Biochem. 48:443-450.

Barrs, H.D. and P.E. Weatherley. 1962. A re-examination of the relative turgidity technique for estimating water deficits in leaves. Austral. J. Biol. Sci. 15:413-428.

Bates, S., R.P. Waldren, and I.D. Teare. 1973. Rapid determination of the free proline in water stress studies. Plant Soil 39:205-208.

Batushansky, A., M. Kirma, N. Grillich, D. Toubiana, P.A. Pham, I. Balbo, H. Fromm, G. Galili, A.R. Fernie, and A. Fait. 2014. Combined transcriptomics and metabolomics of Arabidopsis thaliana seedlings exposed to exogenous GABA suggest its role in plants is predominantly metabolic. Mol. Plant 7:1065-1068.

Beard, J.B. 2001. Turf management for golf courses. 2nd ed. Ann Arbor Press, Chelsea, MI.

Bian, X.J., E. Merewitz, and B.R. Huang. 2009. Effects of trinexapacethyl on drought responses in creeping bentgrass associated with water use and osmotic adjustment. J. Amer. Soc. Hort. Sci. 134:505510.

Blum, A. 1989. Osmotic adjustment and growth of barley genotypes under drought stress. Crop Sci. 29:230-233.

Blum, A. and A. Ebercon. 1981. Cell membrane stability as a measure of drought and heat tolerance in wheat. Crop Sci. 21:43-47.

Bouché, N., A. Fait, D. Bouchez, S.G. Moller, and H. Fromm. 2003. Mitochondrial succinic-semialdehyde dehydrogenase of the gama-aminobutyrate shunt is required to restrict levels of reactive oxygen intermediates in plants. Proc. Natl. Acad. Sci. USA 100:6843-6848.

Bouché, N. and H. Fromm. 2004. GABA in plants: Just a metabolite? Trends Plant Sci. 9:110-115.

Buysse, J. and R. Merckx. 1993. An improved colorimetric method to quantify sugar content of plant tissue. J. Expt. Bot. 44:1627-1629.

Chen, T.H.H. and N. Murata. 2002. Enhancement of tolerance of abiotic stress by metabolic engineering of betaines and other compatible solutes. Curr. Opin. Plant Biol. 5:250-257.

Etemadi, N., M. Sheikh-Mohammadi, A. Nikbakht, M.R. Sabzalian, and M. Pessarakli. 2015. Influence of trinexapac-ethyl in improving drought resistance of wheatgrass and tall fescue. Acta Physiol. Plant. 37:53.

Fry, J. and B.R. Huang. 2004. Applied turfgrass science and physiology. Wiley, Hoboken, NJ.

Hoagland, C.R. and D.I. Arnon. 1950. The solution culture method for growing plants without soil. California Agr. Expt. Circ 347:1-32.

Jiang, Y.W. and B.R. Huang. 2001. Osmotic adjustment and root growth associated with drought preconditioning-enhanced heat tolerance in kentucky bluegrass. Crop Sci. 41:1168-1173. 
Kholova, J., C.T. Hash, P.L. Kumar, R.S. Yadav, M. Kocova, and V. Vadez. 2010. Terminal drought-tolerant pearl millet [Pennisetum glaucum (L.) R. Br.] have high leaf ABA and limit transpiration at high vapour pressure deficit. J. Expt. Bot. 61:1431-1440.

Kinnersley, A.M. and F.J. Turano. 2000. Gamma aminobutyric (GABA) and plant responses to stress. Crit. Rev. Plant Sci. 19:479-509.

Krishnan, S., K. Laskowski, V. Shukla, and E.B. Merewitz. 2013. Mitigation of drought stress damage by exogenous application of non-protein amino acid $\gamma$-aminobutyric acid on perennial ryegrass. J. Amer. Soc. Hort. Sci. 138:358-366.

Krishnan, S. and E.B. Merewitz. 2015. Drought stress and trinexapacethyl modify phytohormone content within kentucky bluegrass leaves. J. Plant Growth Regulat. 34:1-12.

Lu, S.Y., W. Su, H.H. Li, and Z.F. Guo. 2009. Abscisic acid improves drought tolerance of triploid bermudagrass and involves $\mathrm{H}_{2} \mathrm{O}_{2}$ - and NO-induced antioxidant enzyme activities. Plant Physiol. Biochem. 47:132-138.

McCann, H. and B.R. Huang. 2008. Drought responses of kentucky bluegrass and creeping bentgrass as affected by abscisic acid and trinexapac-ethyl. J. Amer. Soc. Hort. Sci. 133:20-26.

McLean, M.D., D.P. Yevtushenko, A. Deschene, O.R.V. Cauwenberghe, A. Makhmoudova, J.W. Potter, A.W. Bown, and B.J. Shelp. 2003. Overexpression of glutamate decarboxylase in transgenic tobacco plants confers resistance to the northern root-knot nematode. Mol. Breed. 11:277-285.

Merewitz, E.B., T. Gianfagna, and B.R. Huang. 2011. Photosynthesis, water use, and root viability under water stress as affected by expression of SAG12-ipt controlling cytokinin synthesis in Agrostis stolonifera. J. Expt. Bot. 62:383-395.

Nayyar, H., R. Kaur, S. Kaur, and R. Singh. 2014. $\gamma$-aminobutyric acid (GABA) imparts partial protection from heat stress injury to rice seedling by improving leaf turgor and upregulating osmoprotectants and antioxidants. J. Plant Growth Regulat. 33:408-419.

Nilsen, E.T. and D.M. Orcutt. 1996. The physiology of plants under stress. Wiley, Hoboken, NJ.

Pessarakli, M. 2007. Handbook of turfgrass management and physiology. CRC Press, Boca Raton, FL.

Renault, H., A.E. Amrani, R. Palanivelu, E.P. Updegraff, A. Yu, J.P. Renou, D. Preuss, A. Bouchereau, and C. Deleu. 2011. GABA accumulation causes cell elongation defects and a decrease in expression of genes encoding secreted and cell wall-related proteins in Arabidopsis thaliana. Plant Cell Physiol. 52:894-908.
Rensburg, L.V., G.H.J. Kruger, and H. Kruger. 1993. Proline accumulation as drought-tolerance selection criterion: Its relationship to membrane integrity and chloroplast ultrastructure in Nicotiana tabacum L. J. Plant Physiol. 141:188-194.

Rivero, R.M., M. Kojima, A. Gepstein, H. Sakakibara, R. Mittler, S. Gepstein, and E. Blumwald. 2007. Delayed leaf senescence induces extreme drought tolerance in a flowering plant. Proc. Natl. Acad. Sci. USA 104:19631-19636.

Serraj, R., B.J. Shelp, and T.R. Sinclair. 1998. Accumulation of $\gamma$-aminobutyric acid in nodulated soybean in response to drought stress. Physiol. Plant. 102:79-86.

Shang, H.T., S.F. Cao, Z.F. Yang, Y.T. Cai, and Y.H. Zheng. 2011. Effect of exogenous $\gamma$-aminobutyric acid treatment on proline accumulation and chilling injury in peach fruit after long-term cold storage. J. Agr. Food Chem. 59:1264-1268.

Shi, S.Q., Z. Shi, Z.P. Jing, L.W. Qi, X.M. Sun, C.X. Li, J.F. Liu, W.F. Xiao, and S.G. Zhang. 2010. Effects of exogenous GABA on gene expression of Caragana intermedia roots under $\mathrm{NaCl}$ stress: Regulatory roles for $\mathrm{H}_{2} \mathrm{O}_{2}$ and ethylene production. Plant Cell Environ. 33:149-162.

Song, H.M., X.B. Xu, H. Wang, H.Z. Wang, and Y.Z. Tao. 2010. Exogenous $\gamma$-aminobutyric acid alleviates oxidative damage caused by aluminium and proton stresses on barley seedlings. J. Sci. Food Agr. 90:1410-1416.

Veerasamy, M., Y.L. He, and B.R. Huang. 2007. Leaf senescence and protein metabolism in creeping bentgrass exposed to heat stress and treated with cytokinins. J. Amer. Soc. Hort. Sci. 132:467-472.

Vijayakumari, K. and J.T. Puthur. 2015. $\gamma$-Aminobutyric acid (GABA) priming enhances the osmotic stress tolerance in Piper nigrum Linn. plants subjected to PEG-induced stress. Plant Growth Regulat., doi: 10.1007/s10725-015-0074-6.

Wang, K.H., X.Z. Zhang, and E. Ervin. 2012. Antioxidative responses in roots and shoots of creeping bentgrass under high temperature: Effects of nitrogen and cytokinin. J. Plant Physiol. 169:492-500.

$\mathrm{Xu}, \mathrm{Y}$. and B.R. Huang. 2009. Effects of foliar-applied ethylene inhibitor and synthetic cytokinin on creeping bentgrass to enhance heat tolerance. Crop Sci. 49:1876-1884.

Zhang, X.Z. and E.H. Ervin. 2004. Cytokinin-containing seaweed and humic acid extracts associated with creeping bentgrass leaf cytokinins and drought resistance. Crop Sci. 44:1737-1745.

Zhang, X.Z., K.H. Wang, and E.H. Ervin. 2010. Optimizing dosages of seaweed extract-based cytokinin and zeatin riboside for improving creeping bentgrass heat tolerance. Crop Sci. 50:316-320. 